\title{
University Educators' Instructional Choices and Their Learning Styles within a Lesson Framework
}

\author{
Mazo, Lucille ${ }^{a}$ \\ ${ }^{\mathrm{a}}$ Department of Communication, MacEwan University, Canada
}

\begin{abstract}
Research on learning styles often focuses on the learning style of the student; however, the learning style of the educator may affect instructional choices and hinder learning. Few studies have addressed the lack of knowledge that exists in universities with respect to educators' learning styles and a lesson framework (development, delivery, and debriefing). This sequential mixed methods study explored university educators' conscious, reflective instructional choices as they related to learning styles application within a lesson. Two theoretical and one conceptual frameworks drew on Kolb's experiential learning theory, Bloom 's, Reigeluth's, and Gagné's instructional design theories and models, and Fiddler's and Marienau's events model of learning from experience. Research questions addressed learning styles, usage patterns, instructional choices, and reflections of university educators within a lesson framework. An online inventory recorded 38 university educators' instructional choices, learning styles, and learning styles patterns within the framework of a lesson. Interviews were conducted with 7 of the university educators to document their conscious reflections regarding their instructional choices. Results from the inventory identified that more than $56 \%$ of university educators applied the accommodation learning style during the stages of development and delivery of a lesson, and 34\% applied the assimilation learning style during the debriefing stage, which were supported by detailed reflections about their instructional choices in relation to their learning styles. The knowledge acquired about learning styles applications during a lesson framework may benefit university educators' teaching, which are foundational to affecting positive social change within academic and social communities.
\end{abstract}

Keywords: instructional choices, learning styles, lesson framework. 


\section{Introduction}

University educators are critical contributors to the development of programs, courses, and lessons. As part of their role, educators are expected to create comprehensive, learnercentered lessons that provide students with key information about topics. There are various factors that influence how educators develop their lesson plans, including context, content, intent, and arrangement of materials (Stark, 2000, p. 413). Additionally, teaching strategies (Gagné, 1987; Bloom, 1956; Grasha, 2002), learning style preferences (Kolb, 1984; Rayner \& Riding, 1997), experiences, events and meaning (Fiddler \& Marienau, 2008), as well as instructional choices, elaborations, and reflections (Kolb, 1984; Reigeluth, 1978) influence educators' decisions about a lesson, and also influence a lesson's learning outcomes in relation to educators' learning styles. Similar to other learners, the learning style preferences of an educator develops early in life and continues to evolve, merge, intermix, and scaffold layers of knowledge, experience, and humanness into a complexly patterned and collaboratively comprehensive system that is used to sustain an educator's advancement of learning and teaching processes.

As such, given that a learner developed his or her learning style preferences prior to becoming a university educator, and given that both learning and teaching style preferences derived from the same individual who moved from one role to the other (learner to educator), it is with alacrity that the university educator's learning style preferences influence the decisions he or she makes when determining reflective instructional choices such as course and lesson content, assignment and assessment activities, delivery and presentation media, and debriefing and reflective approaches to lesson creation. These choices employ the processes of reflection through contemplation, through reflective skills learning, through experimentation (Jarvis et al., 1998, pp. 54-55), as well as through the generation of reflections in the form of ideas and theories both from educators and others (Fiddler \& Marienau, 2008, p. 82). There exists a gap in knowledge about the relationship between university educators' application of their learning style preferences and the reflective instructional decisions they make within the framework of a lesson (development, delivery, and debriefing). Hence, this study examined the relationship between conscious reflective instructional choices and learning styles within the framework of a lesson.

\subsection{Theoretical Foundation}

Two theoretical foundations and one conceptual framework were used in this study: 1) Kolb's (1984) experiential learning theory (ELT) informed learning style application, 2) Bloom's (1956), Reigeluth's (1978), and Gagné's (1987) instructional design theories and models as they supported instructional processes, and 3) Fiddler's and Marienau's (2008) Events Model of Learning from Experience. 


\section{Purpose of the Study}

The purposes of this mixed methods sequential explanatory study were two-fold. The first purpose sought to identify the conscious reflective instructional choices of university educators' within the framework of a lesson (development, delivery, and debriefing), to identify the learning style preferences of university educators as they were applied within this framework, and to determine the learning styles usage pattern based on a coding system resulting from these applied learning style preferences (quantitative).

The second purpose of this study aimed to explain the meaning of university educators' conscious reflective instructional choices using in-depth interviews to capture the reflections, attitudes, and rationales attached to these choices. While the outcomes of the EICLS Inventory (Mazo, 2008) included the identification of university educators' instructional choices within a lesson framework, it did not provide an explanation as to how and why they arrived at their instructional choices. The inclusion of qualitative data gathered in the form of interviews provided a triangulation of the results. In-depth information captured through reflections, attitudes, and rationales provided explanations for university educators' instructional choices.

\section{Research Questions}

The following two main questions were developed to guide the methodology, design, and structure of the study: 1) How are the conscious reflective instructional choices that university educators make within the framework of a lesson (development, delivery, and debriefing) affected by their learning styles?; and 2) When university educators make instructional choices within the framework of a lesson (development, delivery, and debriefing), what conscious reflections about these choices do they make?

\section{Methodology}

The population for this mixed methods sequential explanatory study consisted of a broad spectrum of university educators within the United States and Canada and derived from:the following two groups: 1) Walden University Participant Pool, and 2) United States and Canadian universities via the International Centre for Educators' Styles (ICES) website. Participant characteristics included university educators who taught in various disciplines, whose teaching experiences varied in length of time, who were representative of both male and female genders, who derived from the United States and Canada, and who represented different age groups.

The study was initiated with a quantitative data collection process through the administration of the EICLS Inventory (Mazo, 2008). Educators then consented to participate in an in-depth interview session where they were able to articulate their reflections in relation to the conscious reflective instructional choices they made when 
completing the inventory. The responses that were recorded in the inventory were used to structure the in-depth interviews. Data were analyzed through research statistical software applications.

\section{Results}

An examination of quantitative and qualitative findings revealed two key associations between the EICLS Inventory (Mazo, 2008) responses and the interview transcripts. These two core associations indicated a solid triangulation of the data that supported the nature and focus of this research study.

Regarding the first purpose, conscious instructional choices of educators during a lesson framework (development, delivery, and debriefing), the results from the inventory identified that more than $56 \%$ of university educators applied their dominant learning style of accommodation during the stages of development and delivery of a lesson. This indicated a consistent application of accommodation as their dominant learning style. As well, results from the inventory indicated that $34 \%$ of university educators applied the assimilation learning style during the debriefing stage of a lesson, demonstrating a shift in dominant learning style application. The overall resultant dominant learning style usage pattern was \#34 (of 61 possible patterns), which included the following coding system: EICLSup $=\# 34=$ ac(accommodation in the development stage) and ac(accommodation in the delivery stage) and as(assimilation in the debriefing stage). Overall, the choices recorded in the inventory were supported by the educators' explanations and descriptions found within the interview transcrips.

Regarding the second purpose, meaningful reflections related to university educators' instructional choices, the statistics from the inventory were supported by the interview transcripts. Of the seven educators interviewed, all described the importance of how their personal dominant learning style as a first learner was shaped by their early learning experiences. This then affected how they applied their dominant learning style later in their role as a university educator when actively engaged in the three stages included within a lesson framework. Their reflections indicated that there was a lack of awareness by university educators regarding the effect their learning style had on their instructional choices within a lesson framework.

Overall, within the representative disciplines of arts, business, education, fine arts, and science, there was the emergence of a dominant learning style (accommodation), in both quantitative and qualitative data (triangulation). 


\section{Discussion, Recommendations, and Conclusions}

Understanding the influence that educators' learning styles have on learning when selecting and delivering content for courses and lessons is an important aspect of teaching. It is well known that most educators in higher education do not possess formal education in curriculum development and instructional design. Hence, understanding the process of how educators use their learning styles to develop and deliver their course and lesson materials would provide insight into how higher education institutions can support those educators responsible for curriculum development and course design. As well, this knowledge can potentially be used at the global level, providing understanding of how educators from other cultures and disciplines make instructional choices and how their learning styles influence lesson development, delivery, and debriefing activities. This knowledge can provide best practice considerations for higher education institutions when developing curriculum and designing courses within the context of teaching students. The knowledge learned from this study can potentially enable educators and institutions to engage in positive social change that benefit both academic and social communities.

\subsection{Implications}

Pedagogical implications - First, acquiring basic and core knowledge of higher education educators' personal learning styles is knowledge that higher education institutions and educators can use to improve and enhance instructional choices within a lesson framework. When educators understand these patterns of use and subsequently their impact on lesson creation, they are better equipped with affecting changes within their lesson structure. As such, informed educators can adapt instructional choices within a lesson to increase effectiveness in teaching practices and in student learning. Second, the practice of debriefing or reflecting on a lesson after it is taught is an important finding of this research study. Including reflection as a standard practice for higher education educators so that it becomes part of their everyday teaching methodologies would provide opportunities for teaching innovation and enrichment of lesson content based on these reflections.

Theoretical implications-The outcome of the literature review indicated that the instructional theories of Bloom (1956), Gagne (1987), and Reigeluth (1978) were applied within the framework of a lesson by the educators who were interviewed. These educators provided examples of actual implementations of instructional theories as they were practiced within the classroom. Regarding learning style theorists, Kolb's (1984) ELT was applied within the EICLS Inventory (Mazo, 2008) and used as a foundational basis from which to determine educators' applications of their learning styles during a lesson. This study provides a deeper understanding of how learning styles are applied in a role (university educator) within society that affects significant numbers of individuals (students). 
Empirical implications-Based on the results from the EICLS Inventory (Mazo, 2008), results indicated that the majority of higher education educators applied the accommodation learning style for development and delivery activities, and the assimilation learning style debriefing or reflection after they were completed with the lesson. Empirically, this confirmed that there is a specific dominant learning style usage pattern (\#34) that is applied by educators across the disciplines that participated. There was also a clear indication that each discipline/specialty demonstrated its own dominant learning style usage pattern.

\subsection{Extension of Knowledge within the Field of Higher Education}

Factors that affect instructional choices include 1) the awareness of their own learning styles as they were shaped in early learning years, 2) the application of these learning styles within the context of a lesson framework, and 3) the connection between their learning styles and instructional choices through the conscious reflections of post lesson review (debriefing). In order to develop the framework, instrument, and structure of the study, the EICLS Inventory (Mazo, 2008) was developed and a set of learning styles usage patterns were created.

The EICLS Inventory (Mazo, 2008) was developed and applied within the context of higher education educators. This unique instrument was designed specifically for the purpose of determining how educators apply their learning styles during the framework of a lesson (development, delivery, and debriefing). As such, there is no instrument that currently exists that measures an educator's learning style within a lesson framework. The purpose for developing this instrument was to acquire and record university educators' learning styles applications and activities, which subsequently assists in understanding the relationship between educators, their learning styles, and a lesson framework. This extends and adds to the discipline of higher education, with a focus on educators' learning styles. Additionally, this instrument gathers information that results in determining individual (educator) and group (disciplines) learning styles usage patterns.

A set of learning styles usage patterns was created. The results from the EICLS Inventory (Mazo, 2008) were analyzed and then organized into 61 learning styles usage patterns. These patterns were derived from determining the individual educator's dominant learning styles applications within the framework of a lesson. Then, these dominant learning styles were inserted into a coding system that formed and defined each usage pattern. These unique usage patterns provide a structure that assists in revealing the way in which educators apply their learning styles based on instructional choices within a lesson framework. The coding system and the set of learning styles usage patterns add new knowledge to the discipline of higher education by enabling educators and researchers to determine and observe the behavior of university educators' applications of their own learning styles. Furthermore, these usage patterns provide insights into the behaviors of 
groups of educators based on their teaching discipline. This knowledge can be used by higher education institutions when designing programs for faculty members for the purpose of increasing awareness of how their learning styles are applied through the processes of developing, delivering, and debriefing a lesson. Lessons are at the core of teaching and learning, providing an opportunity for educators to apply learning styles, to teach curriculum content, and to observe students who are in the process of discovering their own learning styles. Information about learning styles applications during a lesson can assist educators in unpacking the complexities of teaching and learning of both stakeholderseducator and student.

\subsection{Recommendations}

Recommendations regarding this study are as follows: 1) Include the use of the EICLS Inventory (Mazo, 2008) as a teaching tool for higher education educators to determine their learning styles and to understand how they are applied within a lesson framework. The resulting learning styles usage patterns can be used to assist educators in comprehending how they apply and adapt their learning styles for the purpose of adapting teaching behavior in relation to lessons; 2) Develop a series of seminars for higher education educators that increase the knowledge of learning styles, instructional design techniques, and the importance of reflection regarding their learning/teaching approaches; and 3) Create an instructional design tool that supports the processes involved in reflecting on a lesson.

\subsection{Conclusions}

Higher education educators bring various factors to the processes related to a lesson (development, delivery, and debriefing). One of these factors is their personal learning styles that were shaped as young learners. It is these learning experiences that educators draw upon as a resource from which to develop, teach, and reflect on a lesson that is taught. This study provides evidence that there is a relationship between a university educator's personal learning style and the consciously reflective instructional choices that they make when researching and developing the content of a lesson. As they create their lessons, they reflect on their past learning experiences that inform them what worked or did not work for their own learning purposes. Educators' learning style preferences were either translated within their own lesson creation or they were rejected based on the learning experiences they had witnessed as learners. Either instructional decision was based on their personal learning style preferences.

The relationship between an educator's personal learning styles and instructional choices can fundamentally change the way a lesson is initially perceived and understood by the educator and then subsequently taught. Understanding this relationship can be established in the third activity of a lesson, debriefing or reflecting on its content and delivery. The role 
of reflection about a lesson is foundational to identifying personal learning styles through usage patterns and then adapting them to the lesson. This requires knowledge of their learning styles preferences, instructional design knowledge to understand the structure of lessons, and comprehension of the critical role that conscious reflection plays in a lesson framework. As such, a lesson involves an elaborate and complex set of knowledge modules that intrinsically work together.

Fundamentally, there is a need for university educators to seek information that will support them in making informative and effective lessons. This benefits teaching practices and student learning, which are inherent and foundational to supporting the positive social change that university educators are positioned within society to accomplish. This research study aimed to advance educators' knowledge in attaining one of society's visions and missions.

\section{References}

Bloom, B.S.. (1956). Taxonomy of educational objectives: The classification of educational goals, Volume 1. London, U.K.: Longmans, Green.

Fiddler, M., \& Marienau, C. (2008). Developing habits of reflection for meaningful learning. New Directions for Adult and Continuing Education, 118, 75-85. Wiley Periodicals, Inc. Published online in Wiley InterScience (www.interscience.wiley.com). doi: 10.1002/ace.297

Gagne, R. (1987). Instructional technology: Foundations. New Jersey, CT: Lawrence Erlbaum Associates, Inc., Publishers.

Grasha, A. (2002). Teaching with style. San Bernardino, CA: Alliance Publishers.

Jarvis, P., Holford, J., \& Griffin, C. (1998). The theory and practice of learning. London, UK: Kogan Page.

Kolb, D. (1984). Experiential learning: Experience as the source of learning and development. Upper Saddle River, NJ: Prentice Hall.

Mazo, L. (2008). Educator's Application of Their Learning Styles Inventory. Knowledge Area Module II: Principles of Human Development (unpublished). Walden University.

Reigeluth, C. M. (1978). In search of a better way to organize instruction: The elaboration theory. Journal of Instructional Development, 2(3), 8-15. Accession Number: ED172788

Rayner, S., \& Riding, R. (1997). Towards a categorisation of cognitive styles and learning styles. $\quad$ Educational Psychology, 17, 5-27. doi: http://dx.doi.org.ezp.waldenulibrary.org/10.1080/0144341970170101

Stark, J. (2000). Planning introductory college courses: Content, context and form. Instructional Science, 28(5/6), 413-438. Retrieved from Education Research Complete database. Accession Number: 16980099 